\title{
Erratum to degenerative mitral valve disease-contemporary surgical approaches and repair techniques
}

Erratum to: Ann Cardiothorac Surg 2017;6:38-46

Degenerative mitral valve disease-contemporary surgical approaches and repair techniques

In the article that appeared on pages 38-46 of the January 2017 issue of the Annals of Cardiothoracic Surgery (ACS) (1), the full name of one of the authors has been transcribed incorrectly.

The correction is as follows: "Gillinov A. Marc" should be corrected as "A. Marc Gillinov".

The publisher regrets this error.

\section{References}

1. Koprivanac M, Kelava M, Alansari S, et al. Degenerative mitral valve disease-contemporary surgical approaches and repair techniques. Ann Cardiothorac Surg 2017;6:38-46.

Cite this article as: Erratum to degenerative mitral valve disease-contemporary surgical approaches and repair techniques. Ann Cardiothorac Surg 2017;6(2):E2. doi: 10.21037/acs.2017.03.20 